\title{
Los paisajes patrimoniales de la Sierra de Huelva. Ensayo metodológico
}

\section{Landscapes and heritage landscapes. A methodological approach applied on 'Sierra de Huelva'}

\author{
Rocío Silva Pérez ${ }^{1}$ y Jaime Jover Báez ${ }^{2}$
}

\begin{abstract}
RESUMEN
A partir del debate sobre la complejidad conceptual del paisaje y los paisajes patrimoniales este artículo propone algunas claves metodológicas para la aprehensión de los paisajes (centrada en el «carácter») y de los paisajes patrimoniales (apoyada en los procesos y vectores de patrimonialización). Como ámbito de ensayo y ejemplificación se ha elegido la Sierra de Huelva, una comarca muy variada en términos paisajísticos y con múltiples valores que han merecido diversos y complejos reconocimientos institucionales y sociales. Se concluye en que la patrimonialización es territorialmente selectiva, pudiéndose identificar distintas áreas en lo que a densidad de vectores e intensidad de reconocimientos patrimoniales se refiere.
\end{abstract}

PAlabras Clave: paisajes; paisajes patrimoniales; vectores patrimoniales; procesos de patrimonialización; Sierra de Huelva.

\footnotetext{
AbStract

Acknowledging the complexity of both concepts landscapes and heritage landscapes, a few methodological keys (embedded in a broader framework) are explored in order to understand landscapes (through their character) and heritage landscapes (through heritagetisation processes and vectors). Our methodological approach is tested on

${ }^{1}$ Profesora Titular, Departamento de Geografía Humana, Universidad de Sevilla, rsilva@us.es.

2 Becario de Investigación, Departamento de Geografía Humana, Universidad de Sevilla, jjover@us.es.
} 
'Sierra de Huelva', a mountainous county region on west Andalusia that has a large variety of landscapes dotted with cultural values, many of which have been both institutionally and socially recognised. It is concluded that heritagetisation is spatially selective and some areas can be identified by means of the density and the intensity of its heritage vectors.

KEY WORDS: landscapes; heritage landscapes; heritage vectors; heritagetisation processes; Sierra de Huelva.

\section{1.- CONSIDERACIONES PREVIAS}

La promulgación hace tres lustros del Convenio Europeo del Paisaje (en adelante CEP. Consejo de Europa, 2000) supuso un revulsivo en materia de paisaje, alentando la creación de centros de estudio y reavivando el debate conceptual y metodológico en torno a la identificación, la caracterización y la valoración de los paisajes (Scazzosi, 2004; Gómezy Riesco, 2010). La identificación ha sido abordada a través de realización de atlas y catálogos (Mata y Sanz, 2004; Junta de Andalucía, 2005); para la caracterización se ha acudido la noción de «carácter», que es como la huella dactilar de cada paisaje resultante de la combinación, única e irrepetible en cada ámbito, entre un medio físico-natural determinado, unos procesos de construcción histórica y un elenco de representaciones sociales; en lo que a valoraciones se refiere, se considera al paisaje como una realidad medial entre el mundo exterior al individuo (paisajes objetivos $u$ objetivables) y sus representaciones y valoraciones sociales (paisajes subjetivos y recreaciones creativas) (Berque, 2009). Esta última dimensión perceptiva y cualificadora ha sido abordada a través de estudios transdisciplinarios a los componentes principales, los atributos y los núcleos de sentido de cada paisaje (Ojeda, 2013).

En paralelo a la asunción de los postulados del Convenio ha crecido el interés por determinados paisajes de especial valor cultural, conocidos y reconocidos institucionalmente por nominaciones y/o figuras de protección del patrimonio cultural, natural y/o territorial. Sólo en España podrían citarse las siguientes nociones: paisajes culturales, zonas patrimoniales, paisajes de interés cultural, lugares de excepcional valor paisajístico, paisajes singulares, paisajes sobresalientes, paisajes protegidos, etc.; todas ellas asimilables a «paisajes patrimoniales» que es la denominación que se considera más acertada (Fernández y Silva, 2015). Se trata de conceptos que cabe calificar de segunda generación, resultantes de la combinación de otros previos ya de por sí polisémicos y cambiantes (patrimonio y paisaje) (Gómez Mendoza, 2013). Sobrepasa el cometido de estas páginas adentrarse en los entresijos de esa 
combinación, que está en la base del debate actual sobre los paisajes patrimoniales; pero es preciso aclarar una serie de supuestos:

- Todos los paisajes contienen valores patrimoniales y son patrimoniables; pero como ha sido recientemente señalado "patrimonio y patrimonialización implican un ejercicio de selección de lo significativo o relevante dentro del amplio universo de bienes patrimonializables» (Mata, de Meer y de la Puente, 2012: 144) y la categoría de paisajes patrimoniales debe circunscribirse a aquellos paisajes que por su carácter merezcan ser objeto de reconocimiento y tutela.

- La conversión de un paisaje en paisaje patrimonial se opera a raíz de procesos de apropiación social y de asignación de valores, que pueden actuar en un doble sentido: de «abajo arriba», cuando es la sociedad civil la que incita a la patrimonialización (Clark y Drury, 2002; citado por Mata, 2010); y, de «arriba abajo», que suele ser lo más habitual, cuando la valoración patrimonial deviene de la presencia de refrendos normativo-institucionales y/o de la existencia de estudios académicos de relativo impacto social (Prats, 1997; Besse, 2009). Existe una gran permeabilidad entre ambos mecanismos, cuya sola presencia refuerza la patrimonialidad de ciertos paisajes, a la par que induce a la aparición de agentes y normas que se erigen en capital social indispensable para la gestión de tales paisajes.

- La identificación (social y/o institucional) con los paisajes es selectiva; no se ejerce sobre todos sus componentes, sino que se aglutina en torno a lo que se ha venido en denominar vectores de patrimonialización, que son atributos (intangibles) asociados a determinados componentes (materiales e inmateriales) de los paisajes, ya se trate de piezas aisladas de carácter natural y/o cultural a las que se asigna un especial valor (como por ejemplo riscos, oquedades, manantiales, castillos, ermitas, monasterios); de ejes de comunicación (vías pecuarias, itinerarios culturales); de actividades económicas con una potente proyección espacial y particularmente valoradas (enclaves mineros, huertas, viñedos, dehesas); de prácticas culturales («saber hacer», manifestaciones folkóricas), etc. (Fernández y Silva, 2015).

El objeto de este artículo es el planteamiento de un procedimiento metodológico para el estudio de los paisajes patrimoniales a través de la Sierra de Huelva. Se parte de la siguiente hipótesis: el «carácter» es lo que hace diferente a unos paisajes de otros, pero no necesariamente es lo que lo hace valioso. Esta valía es el resultado de procesos de asignación social e institucional de significados culturales a determinados componentes de los 
paisajes (los vectores patrimoniales). El artículo se estructura en dos partes: la primera identifica y caracteriza los paisajes de la Sierra de Huelva; y la segunda describe los valores patrimoniales y los procesos de patrimonialización que convierten aquellos valores en vectores ${ }^{3}$ y a los paisajes en paisajes patrimoniales.

Como fuentes de información se han utilizado los trabajos reseñados en la bibliografía. Para la identificación de los valores se ha recurrido al Catálogo General del Patrimonio Histórico Andaluz y a la Red de Espacios Naturales Protegidos de Andalucía (RENPA). El estudio de los procesos de patrimonialización se ha abordado, en el caso de la patrimonialización de «arriba hacia abajo», a partir de las declaraciones institucionales de Bienes de Interés Cultural y Espacios Naturales Protegidos; para la patrimonialización de «abajo hacia arriba» se ha acudido al tejido asociativo (a través de los blog y sus páginas web de las principales asociaciones). Todo ello, junto al trabajo de reconocimiento territorial, permitió la realización de un primer diagnóstico paisajístico-patrimonial de esta sierra y una primera propuesta de posibles vectores patrimoniales, convertida en definitiva después de ser compartida con la sociedad civil representada en las XXX Jornadas de Patrimonio de la Sierra de Huelva (Zufre, marzo de 2015) donde los autores de este trabajo participaron con una ponencia (Silva y Fernández Salinas, 2015).

\section{2.- IDENTIFICACIÓN Y CARACTERIZACIÓN DE LOS PAISAJES SERRANOS ONUBESES}

La Sierra de Huelva se localiza en el sector noroccidental de la Sierra Morena andaluza y ocupa una superficie de 300.800 ha (Plan de Ordenación del Territorio de Andalucía, POTA). El Atlas de Paisajes de España (Mata y Sanz, 2004) identifica en ella hasta once unidades de paisaje, integradas en cuatro tipos, que a su vez se agregan en dos asociaciones paisajísticas (véase la tabla 1); ello permite hacerse una idea de su complejidad paisajística interna.

${ }^{3}$ La alusión diferenciada a «valores» (también denominados «referentes» y/o «argumentos») y «vectores» patrimoniales no pretende incorporar nuevas nociones ni acrecentar la confusión terminológica; persigue diferenciar entre el diagnóstico académico de los referentes patrimoniales presentes en todos los paisajes y la asunción social y/o institucional de algunos de tales valores como condensadores patrimoniales, convertidos en virtud de ello en vectores de patrimonialización. 
FIGURA 1

LA SIERRA DE HUELVA: LOCALIZACIÓN Y DELIMITACIÓN

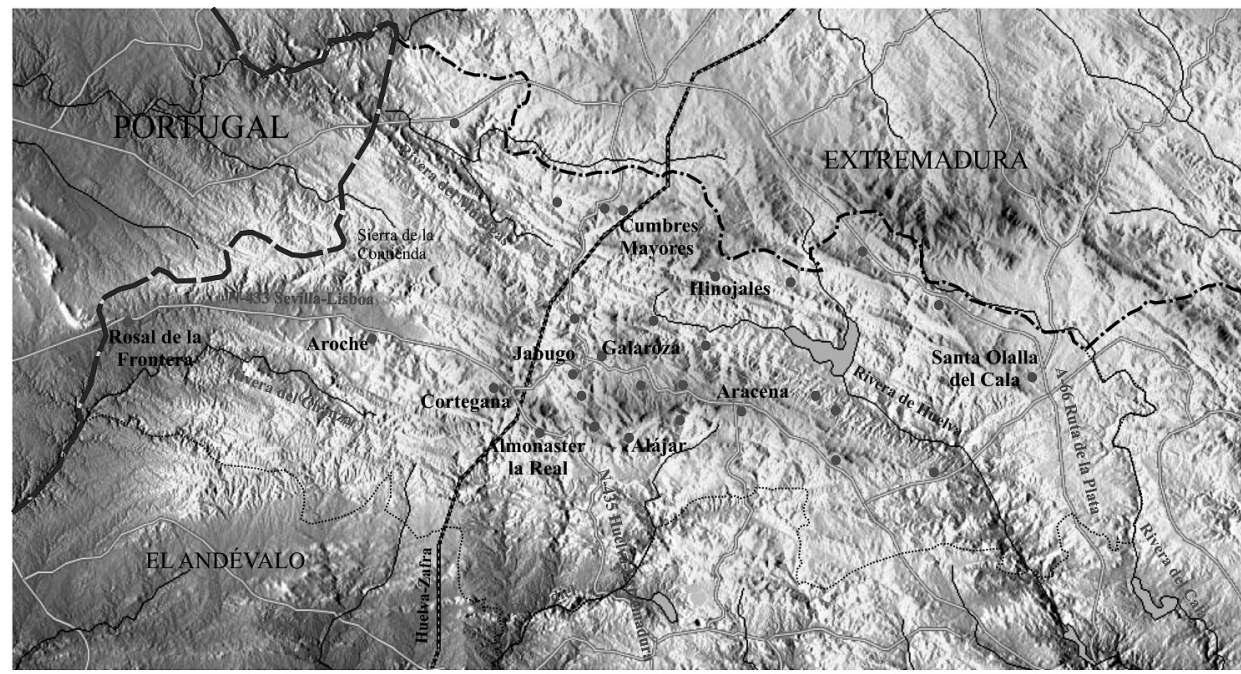

Leyenda:

- Frontera nacional

L. Límite autonómico

- Núcleos de población (Cabeceras)

Carreteras
Ferrocarril

- Ríos
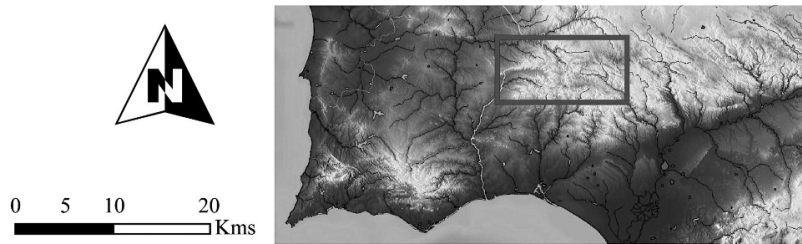

Fuente: http://www.maps-for-free.com/. Elaboración propia.

Los principales rasgos definitorios del carácter de aquellos paisajes son la diversidad y la persistente condición histórica de frontera que no es incompatible, sino todo lo contrario, con la permeabilidad cultural entre ambos lados allí donde esa frontera se convierte en raya (la Raya de Portugal) (Villa, 2011). 
TABLA 1

CLASIFICACIÓN DE LOS PAISAJES DE LA SIERRA DE HUELVA EN EL ATLAS DE LOS PAISAJES DE ESPAÑA.

\begin{tabular}{l|l|l|l}
\hline $\begin{array}{l}\text { Asociaciones de } \\
\text { Tipos de Paisaje }\end{array}$ & Tipos de Paisaje & \multicolumn{1}{|c}{ Subtipo } & \multicolumn{1}{c}{ Unidades de Paisaje } \\
\hline $\begin{array}{l}\text { Sierras, cerros y } \\
\text { valles andaluces, } \\
\text { levantinos y } \\
\text { extremeños (7) }\end{array}$ & $\begin{array}{l}\text { Sierras y valles de } \\
\text { Sierra Morena (27) }\end{array}$ & $\begin{array}{l}\text { Del Norte de } \\
\text { Huelva y Sevilla }\end{array}$ & $\begin{array}{l}\text { Cumbres Mayores y de San Bartolomé } \\
(27.01) \\
\text { Sierra de Hinojales (27.02) } \\
\text { Sierra de Aroche (27.03) } \\
\text { Valle del Río Chanza (27.04) } \\
\text { Sierra de Aracena Oriental (27.05) } \\
\text { Sierra de Aracena Occidental (27.06) } \\
\text { Sierra de Nerva (27.07) }\end{array}$ \\
\cline { 2 - 4 } & $\begin{array}{l}\text { Laderas serranas y } \\
\text { valles de Sierra Mo- } \\
\text { rena al Guadalquivir } \\
(34)\end{array}$ & Occidentales & $\begin{array}{l}\text { Valle de la Rivera de Huelva (34.06) } \\
\text { Laderas del Guadiamar en Sierra Mo- } \\
\text { rena (34.07) }\end{array}$ \\
\hline $\begin{array}{l}\text { Penillanuras y } \\
\text { piedemontes } \\
(12)\end{array}$ & $\begin{array}{l}\text { Vertientes, cerros y } \\
\text { lomas del Andévalo } \\
(35)\end{array}$ & & $\begin{array}{l}\text { Vertientes del Andévalo al Chanza } \\
(35.04)\end{array}$ \\
\cline { 2 - 4 } & $\begin{array}{l}\text { Penillanuras surocci- } \\
\text { dentales (48) }\end{array}$ & $\begin{array}{l}\text { Adehesadas sobre } \\
\text { granitos }\end{array}$ & $\begin{array}{l}\text { Penillanuras de Santa Olalla del Cala } \\
(48,37)\end{array}$ \\
\hline
\end{tabular}

Fuente: Mata y Sanz, 2004.

\subsection{Delimitación y rasgos básicos del carácter paisajístico}

La Sierra de Huelva es una comarca administrativamente bien delimitada, pero sus contornos naturales y culturales son poco nítidos. Sus confines septentrionales, occidentales y orientales concuerdan, respectivamente, con los límites autonómico (entre Andalucía y Extremadura), estatal (raya de Portugal) y provincial (entre Sevilla y Huelva); por el Sur sus límites son menos precisos y la Sierra se prolonga en suave caída por su pié de monte (El Andévalo) (véase la figura 1). Esa delimitación administrativa no tiene un correlato en límites físico-territoriales bien definidos: su sector Nordeste constituye una prolongación de la penillanura extremeña; por el Oeste el río Guadiana se adentra en

\footnotetext{
${ }^{4}$ El número entre paréntesis reproduce la numeración del Atlas.
} 
Portugal y se diluye la frontera natural con el Estado luso; por el Este el límite natural se retrotrae hasta la falla tectónica del Viar (situada en el sector centrooccidental de la Sierra Norte de Sevilla).

En términos físico-naturales la Sierra de Huelva es una comarca compleja y muy diversa. El repetitivo esquema orográfico de Sierra Morena de cerros e interfluvios alineados en sentido WNW-ESE se rompe en ella, debido al elevamiento alpino en su zona central de un murallón calizo (de dirección W-E). Ese murallón actúa como divisoria de aguas y compartimenta el territorio en cuatro cuencas hidrográficas: Chanza, Múrtigas, Rivera de Huelva, Tinto y Odiel, en el sentido de la agujas del reloj. Las condiciones climáticas se adaptan y reproducen aquella compartimentación fisiográfica y se traduce en grandes contrastes entre las sierras centrales del eje Aracena-Cortegana (con precipitaciones por encima de los 1.000 milímetros anuales y temperaturas máximas entre $24-26^{\circ}$ ) y el resto del territorio (con lluvias que raramente alcanzan los 700 milímetros y temperaturas máximas de más de $35^{\circ}$ ). En la composición del roquedo domina la impermeabilidad de las rocas metamórficas (pizarras, filitas y esquistos), que alterna con complejos vulcano-sedimentarios en el sector central más elevado y en el franco norte lindante con Extremadura y con intrusiones graníticas en el sector suroriental colindante con el Corredor de la Plata.

La intensidad y diversidad del poblamiento es igualmente singular en esta sierra y su disposición interna también es muy dispar. La red de asentamientos más tupida se ubica en las sierras centrales; allí se sitúan las dos cabeceras comarcales (Aracena: 7.812 habitantes y Cortegana: 4.939 habitantes) y un numeroso cortejo de pequeños y pintorescos núcleos de población ${ }^{5}$ y sus correspondientes aldeas ${ }^{6}$. Las restantes poblaciones serranas, también de pequeñas dimensiones, se distribuyen por los valles del Chanza (donde destacan Aroche y Rosal de la Frontera) y el Rivera del Huelva (donde se sitúan Zufre, Puerto Moral, Corteconcepción y Cortelazor); o se ubican en las penillanuras septentrionales colindantes con Extremadura (Cumbres Mayores, Cumbres de Enmedio y Cumbres de San Bartolomé) o vigilando el Corredor de la Plata (Cala y Santa Olalla de Cala).

\footnotetext{
${ }^{5}$ Exceptuando a Jabugo (2.288 habitantes), las cabeceras municipales de este promontorio central raramente superan los 1.000 habitantes (Santa Ana la Real, Fuenteheridos, Alajar, Galaroza); y aún son más numerosas las de menos de 500 e incluso de 200 habitantes (Castaño del Robledo, Puerto Moral, Linares de la Sierra, Los Marines)

635 aldeas según el último Censo de Población: 12 en Almonaster; 6 en Aracena; 5 en Cortegana; 4 en Aroche y otras tantas en Alájar.
} 
La disparidad fisiográfica depara una multiplicidad de parajes (cumbres, valles, pié de montes, etc.) y ambientes (solanas, umbrías, barloventos, sotaventos, etc.). En torno a las poblaciones se ha ido configurando un cortejo de usos agro-forestales: espacios agrarios de reducida extensión en las primeras aureolas conformando áreas de regadíos (Galaroza e Hinojales-Cañaveral de León) o ruedos cerealistas y olivareros allí donde no existen disponibilidades hídricas; dehesas en penillanuras, valles encajados y embalsados (como los del Múrtiga y el Rivera de Huelva) y llanuras abiertas (como «los llanos de la Belleza» en el valle del Chanza); bosques de castaños en las umbrías de las sierras centrales; repoblaciones de eucaliptos en las cercanías del Andévalo, etc.

Se trata, en suma, de una sierra extremadamente diversa en cuanto a morfologías y usos, con sus correspondientes correlatos paisajísticos, pudiéndose diferenciar un área central, pintoresca y tópica (las sierras del eje AracenaCortegana) y cuatro periferias: la fronteriza (Sierra de la Contienda, en Aroche); la extremeña de penillanura (municipios de Las Cumbres) y de paso a través de la sierras vulcano-sedimentarias del Noreste (Calas, Cañaveral, Hinojales); la sevillana (Corredor de la Plata); y la andevaleña (el Sur minero).

Por su excepcionalidad y singularidades paisajística destacan las sierras centrales, que pese a ser las más elevadas son las mejor comunicadas con el exterior: por ellas discurren el ferrocarril Huelva-Zafra y las carreteras N-433 Sevilla-Lisboa, N-435 Huelva-Extremadura y A-470 Aracena-Cortegana. La alternancia de exposiciones propiciadas por el relieve depara en estas sierras centrales parajes muy variados y de una gran singularidad, particularmente en las umbrías, dominadas por el verdor de las arboledas de los bosques galería y por los usos intensivos (huertas) y extra-mediterráneos del suelo (castañares). Su poblamiento disperso y polinuclear (poco común en Andalucía), la tupida red de caminos y la compartimentación minifundista contribuyen a la excepcionalidad y singularidad de sus paisajes, convertidos -en razón de la accesibilidad- en foco de convergencias de muchas miradas y en una las principales áreas de concentración económica serrana (industria chacinera de El Repilado y emergente turismo rural).

\subsection{La construcción del territorio. Hitos históricos, resultantes patrimo- niales y miradas creativas}

Los primeros indicios de ocupación humana datan de la prehistoria; son numerosos los vestigios neolíticos y calcolíticos en cuevas y oquedades y la 
profusión de dólmenes megalíticos (véase la tabla 2). También abundan las evidencias de su intensa romanización: restos de ciudades, yacimientos mineros, monumentos funerarios, edificaciones dispersas en el medio rural, etc. Las tramas territoriales más visibles se trazan en la Edad Media, que ha legado exuberantes regadíos tradicionales de herencia andalusí y una estructura de poblamiento muy potente, con núcleos tradicionalmente adosados a castillos. De origen medieval es la persistente condición de frontera, primero con el Islam (siglos VIII-XI) y, más tarde (tras conquista cristiana por órdenes militares leonesas y portuguesas de finales del s. XII y principios del xiII, incorporándose al Reino de Sevilla), con Portugal en una disputa que se prolonga hasta 1926 (Carmona Ruiz, 1998). Son referentes patrimoniales de ese carácter fronterizo los castillos de la denominada Banda Gallega (véase la tabla 2), los topónimos (de sierra y dehesa) alusivos a La Contienda (antiguos terrenos comunales disputados por los concejos de Moura, Aroche y Encinasola), amén de otros ejemplos puntuales como la población ilustrada de tejido urbano planificado de Rosal de la Frontera o el estilo renacentista manuelino de la fachada principal de la iglesia de Almonaster la Real.

De origen medieval es también el sistema de poblamiento, compuesto, como se ha dicho, por numerosos núcleos de paisajes muy contrastados y tejidos bien conservados. Algunas de aquellas poblaciones conocieron a finales del XIX y principios del xx un auge industrial nada despreciable, que ha legado valiosos exponentes de arqueología industrial: antiguas fábricas de electricidad y harina y edificios diseñados por Aníbal González como Tiro Pichón (en El Repilado, Jabugo). El mismo arquitecto diseñará el casino de Arias Montano, el Ayuntamiento de Santa Catalina y el lavadero de la Fuente en Aracena.

El éxodo rural de los años sesenta y setenta del siglo pasado dejó importantes secuelas en forma de deterioros paisajísticos y abandonos y ruinas edificatorias; pero la Sierra de Huelva siguió estando relativamente poblada en términos comparativos con los vacíos experimentados por otras áreas de Sierra Morena. Desde mediados de los ochenta el nuevo paradigma ambiental y el desarrollo del turismo rural ha abierto nuevas fuentes de ingresos y la promovido nuevas filiaciones patrimoniales. Los resultados de estos procesos, aún en ciernes, son contradictorios: creación de una nueva identidad comarcal a partir de la declaración en 1989 del Parque Natural de la Sierra de Aracena y Picos de Aroche y recuperaciones versus banalizaciones y deterioros de pasajes asociados a los reconocimientos institucionales y a la emergencia del turismo rural. 
El carácter de los paisajes serranos onubenses está impregnado de numerosas miradas creativas que connotan y singularizan algunos de sus parajes y los elevan a la categoría de paisajes canónicos. Este es el caso de la Peña de Arias Montano, uno de los lugares más emblemáticos de la sierra que debe su nombre al humanista de la Corte de Felipe II, que en el siglo XvI lo eligió como espacio de retiro y meditación confiriéndole con sus escritos una fuerte carga identitaria y un elevado valor simbólico:

En este retiro donde vivo ahora rústicamente, hay cuevas profundas y parajes abovedados formados por ásperos peñascos, en parte debidos al capricho de la naturaleza y en parte, como sospecho, ampliados y excavados por la mano del hombre (cuando en estos lugares habitaban los sarracenos). Fundamento esta afirmación en vestigios de vajillas de barro con huesos humanos que a veces vemos enterrados en estos antros (De varia Republica Cap. VI. Amberes, 1590; citado en Sánchez y Castillo, 1999).

Existen otras muchas exaltaciones literarias de esta sierra que recalan en los componentes sencillos y cotidianos de sus paisajes: el agua, el viento, el humo o los troncos de los árboles, muy presentes entre sus poetas actuales (Manuel Moya; Antonio Moreno Jurado; Federico Martín) y recreados por la pintura intimista de Paco Broca.

«Fuenteheridos»

Alfanje de dos filos

$y$ siete caños.

Agua abierta que calma

los desengaños.

Sangre verde en la herida

de los castaños.
«Río Múrtigas»

...Para que el viento, madre, se duerma en el envés de las hojas que sueñas mi infancia y tu vejez. Cógeme de la mano.

Cógeme.

J.A. Moreno Jurado (1995).

3. Claves Patrimoniales de los paisajes Serranos onubenses

\subsection{Valores y vectores patrimoniales. Claves metodológicas para su determinación}


TABLA 2

\section{VALORES PATRIMONIALES DE LOS PAISAJES SERRANOS ONUBENSES}

\begin{tabular}{|c|c|}
\hline \multirow[t]{3}{*}{ 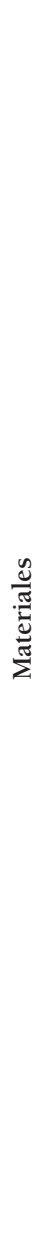 } & 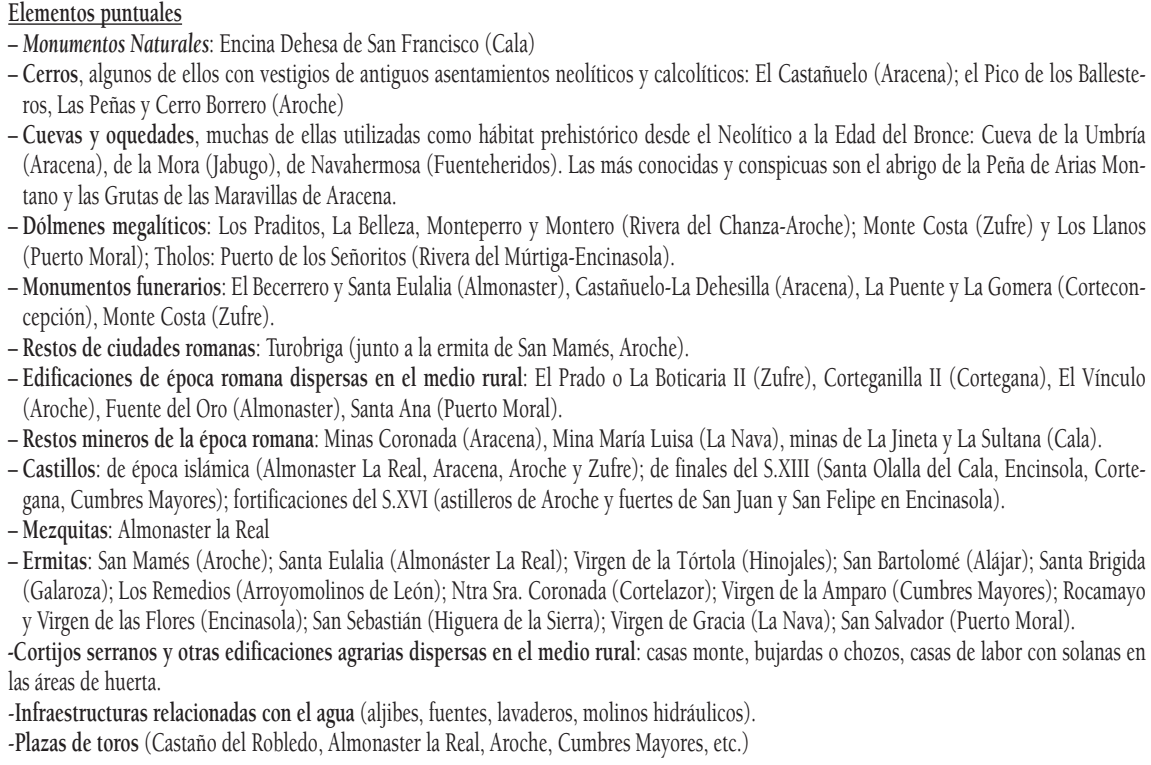 \\
\hline & $\begin{array}{l}\text { Elementos lineales } \\
\text { - Cursos de agua jalonados por bosques galería } \\
\text { - Ejes de comunicación: restos de la Vía Romana Rio Tinto, Aroche, Beja; antigua línea ferroviaria Minas de Cala-San Juan de Aznalfarache; } \\
\text { caminos rurales y vías pecuarias. } \\
\text { - Restos de acueductos romanos (Fuente Seca) } \\
\text { - Sistemas de acequia (lievas) } \\
\text { - Muros de piedra seca (en ruedos y dehesa) }\end{array}$ \\
\hline & $\begin{array}{l}\text { Áreas } \\
\text { - Entramados urbanos (medievales y nuevas poblaciones de tejido urbano planificado) } \\
\text { - Regadíos tradicionales } \\
\text { - Antiguas eras empedradas } \\
\text { - Bosques de castaños } \\
\text { - Dehesas }\end{array}$ \\
\hline 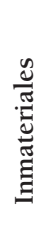 & $\begin{array}{l}\text { - Romerías, algunas de ellas de carácter supralocal: Nuestra Señora de los Ángeles (Alájar), San Mamés (Aroche), Santa Eulalia (Almonaster), } \\
\text { San Antonio (Cortegana) } \\
\text { - Fiestas populares: Cruces de Almonaster, Cabalgata de Reyes Magos de Higuera de la Sierra, fiesta de los Jarritos (Galaroza), fiesta de los } \\
\text { Rehiletes (Aracena). } \\
\text { - Danzas y rituales: Danza de Hinojales, danzantes del Lunes de Albilillo de Cumbres Mayores, antiguas danzas del Pañuelo de Encinasola. } \\
\text { - Cantes: fandango morocho de Encinasola, jota serrana, canciones tradicionales } \\
\text { - Artesanías: carpinterías de Galaroza, alfarerías de Aracena y Cortegana, fábrica de romanas de Cortegana, guarnicionería de Aroche } \\
\text { - Oficios Tradicionales }\end{array}$ \\
\hline
\end{tabular}

Fuentes: IAPH, 2010; Zoido, 2012; Catálogo General de Patrimonio Histórico Andaluz y Red de Espacios Naturales Protegidos (RENPA). Elaboración propia.

Estudios Geográficos, Vol. LXXVII, 281, pp. 647-670, julio-diciembre 2016 ISSN: 0014-1496, eISSN: 1988-8546, doi: 10.3989/estgeogr.201622 
Los procesos de construcción histórica y las miradas creativas han deparado una gran una riqueza y diversidad de valores o argumentos patrimoniales sistematizados en la tabla 2. En ellas se diferencia entre bienes patrimoniales de índole material e inmaterial (o etnográfico). Los primeros se subdividen, a su vez, en: 1) Elementos puntuales de raigambre natural y/o cultural, insertos en tejidos urbanos y/o dispersos por el medio rural (iglesias, castillos, mezquitas ermitas, monumentos funerarios, restos de ciudades y edificaciones romanas, yacimientos mineros, dólmenes, cuevas y oquedades, y un largo etcétera); 2) Ejes y/o elementos lineales de los paisajes (cursos de agua, vías de comunicación, restos de antiguos acueductos, acequias o «lievas», muros de piedra, etc.); y 3) Usos y/o áreas funcionales, algunas de las cuales son en sí mismo paisajes (conjuntos urbanos, regadíos tradicionales, antiguas eras empedradas, bosques de castaño, dehesas, etc.).

Muchos de esos referentes patrimoniales han sido mencionados anteriormente, en particular aquéllos de índole monumental relacionados con las bases físico naturales y la construcción histórica del territorio (monumentos naturales y culturales). Mención aparte merece aquel otro patrimonio menos conocido y raramente inventariado, vinculado a las actividades económicas de raigambre agropecuaria (zahúrdas, tinaones, muros de piedra, fuentes, abrevaderos, albercas, acequias) y a actividades minero-industriales (ferrocarriles, cortas, hornos de cal, malacetes, estaciones, puentes, fábricas, almazaras, destilerías) y socio recreativas (balnearios, plazas de toros). Otro tanto cabe señalar respecto al patrimonio etnológico de esta sierra, que es igualmente rico y variado: celebraciones relacionadas con la religiosidad popular (romerías de los entornos de las ermitas, Semana Santa, Cruces de Mayo, Cabalgata de Reyes de Higueras de la Sierra), fiestas vinculadas a faenas agrarias (matanzas, fiesta de «Los Jarritos» de Galaroza), danzas (algunas de ellas inscritas en el Catálogo General de Patrimonio Histórico Andaluz: danzas del Corpus y de la Virgen de la Esperanza en Cumbres Mayores, de la Virgen de la Tórtola en Hinojales y del Pandero en Encinasola). E igualmente destacables son las manifestaciones artesanas relacionadas con la alfarería y el trabajo del corcho (Cortegana), con la fabricación de muebles y sillas de eneas pintadas a mano (Galaroza), con la cestería de varetas de olivo (Cumbres de San Bartolomé) y con la curación artesana de los derivados del cerdo ibérico (Jabugo y Cumbres Mayores).

Buena parte de esos valores y vectores patrimoniales son susceptibles de ser localizados en un mapa, pero su elaboración reviste cierta complejidad y requiere un procedimiento metodológico propio sobre el que habrá que seguir trabajando. Hay que tener en cuenta que muchos referentes patrimoniales de carácter puntual y lineal se sobreponen o que se incardinan con las «áreas pa- 
trimoniales» (caso de los hitos monumentales urbanos integrados en conjuntos históricos o de las redes de acequias y los muros de piedra insertos en los paisajes de los regadíos tradicionales); que buena parte de las «áreas patrimoniales» tienen límites poco definidos; y que los elementos inmateriales no siempre son fáciles de localizar. Todo ello, y en particular las superposiciones (tipológicas y escalares) de los referentes y vectores patrimoniales, conlleva una dificultad a la hora de cartografiarlos.

Los referentes patrimoniales reseñados en la tabla 2 impregnan el «carácter» paisajístico serrano; pero no todos ellos reciben filiaciones socio-institucionales equiparables y se erigen en vectores patrimoniales. El tránsito desde los valores a los vectores patrimoniales implica un avance cualitativo y requiere un procedimiento metodológico complementario de profundización bibliográfica (Recio Moya, 1995; IAPH, 2010; Ojeda y Silva, 2002; Zoido, 2012) y reconocimiento territorial, a la par que necesita de la aprehensión de las valoraciones paisajísticas de los agentes e interlocutores sociales locales. Esto último ha sido posible gracias a la participación de los autores de este artículo en las XXX Jornadas de Patrimonio de la Comarca de la Sierra (Silva y Fernández Salinas, 2015); ello ha permitido la diferenciación de los siguientes vectores patrimoniales:

a) Condición de frontera que, como se ha visto, impregna el «carácter» serrano onubense, y que se concreta en la doble línea defensiva de castillos y fortificaciones de la denominada Banda Gallega (véase la figura 2).

\section{FIGURA 2}

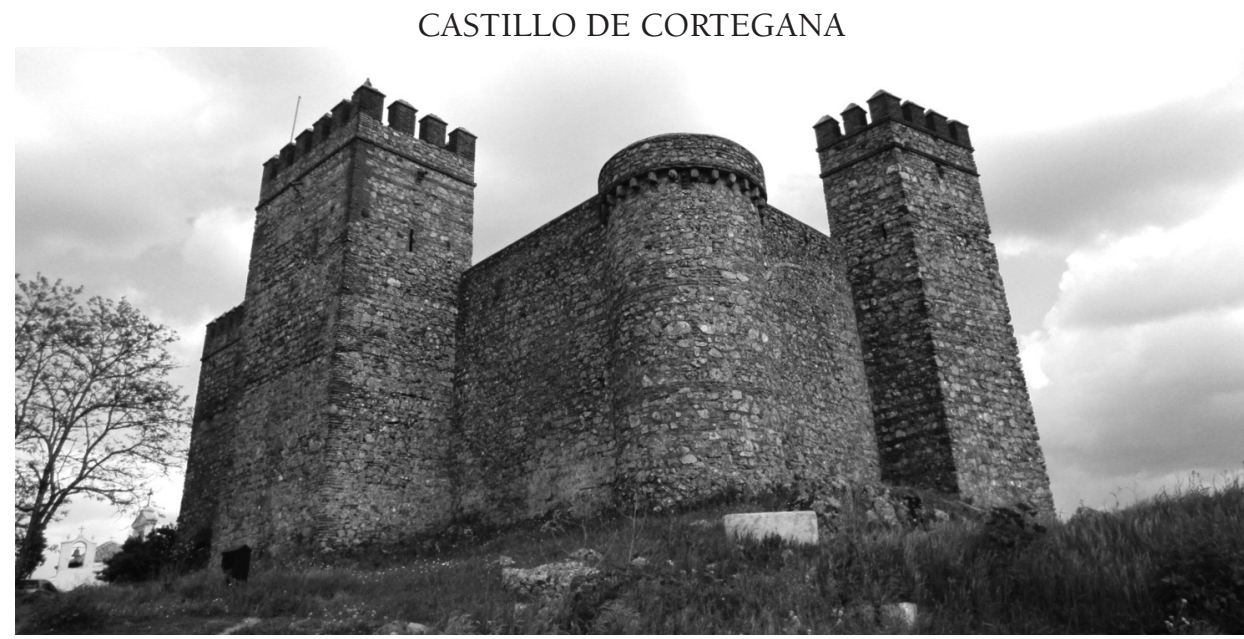

Fuente: Fernández Salinas, V. (Foto realizada en abril de 2014). 
b) Peñas, cuevas y oquedades, con dos concreciones bien localizadas: Cueva y Peña de Arias Montano, a la que ya se ha hecho mención, cuya patrimonialidad es producto de una multiplicidad de atributos -valor paisajístico interno, elevada intervisibilidad (La Peña constituye un hito paisajístico destacado y desde ella se obtienen espectaculares vistas del Sur de la provincia de Huelva, véase la figura 3), presencia de la ermita de la Virgen de los Ángeles y entramado de cuevas entre las que se encuentra el Palacio Osucro de la obra de Arias Montano-. Otro vector es la Gruta de las Maravillas (Aracena), abierta al público desde 1914 y muy conocida y visitada por escolares y excursionistas de distintas generaciones.

FIGURA 3

VISTAS DESDE LA PEÑA DE ARIAS MONTANO

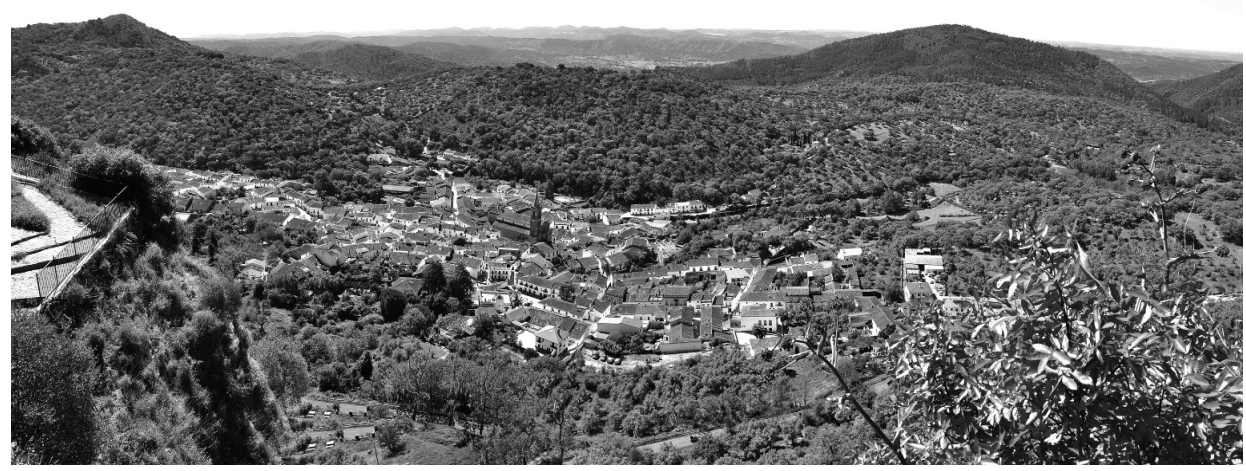

Fuente: Fernández Salinas, V. (Foto realizada en junio de 2014).

c) Ermitas de afluencia supralocal y con un especial arraigo: Nuestra Señora de los Ángeles (en la Peña de Arias Montano, Alájar), San Mamés (ubicada junto a la antigua ciudad romana de Turobriga, Aroche, véase la figura 4); Santa Eulalia (levantada sobre un antiguo mausoleo romano, en Almonaster la Real); y San Antonio (Cortegana). 
FIGURA 4

ERMITA DE SAN MAMÉS

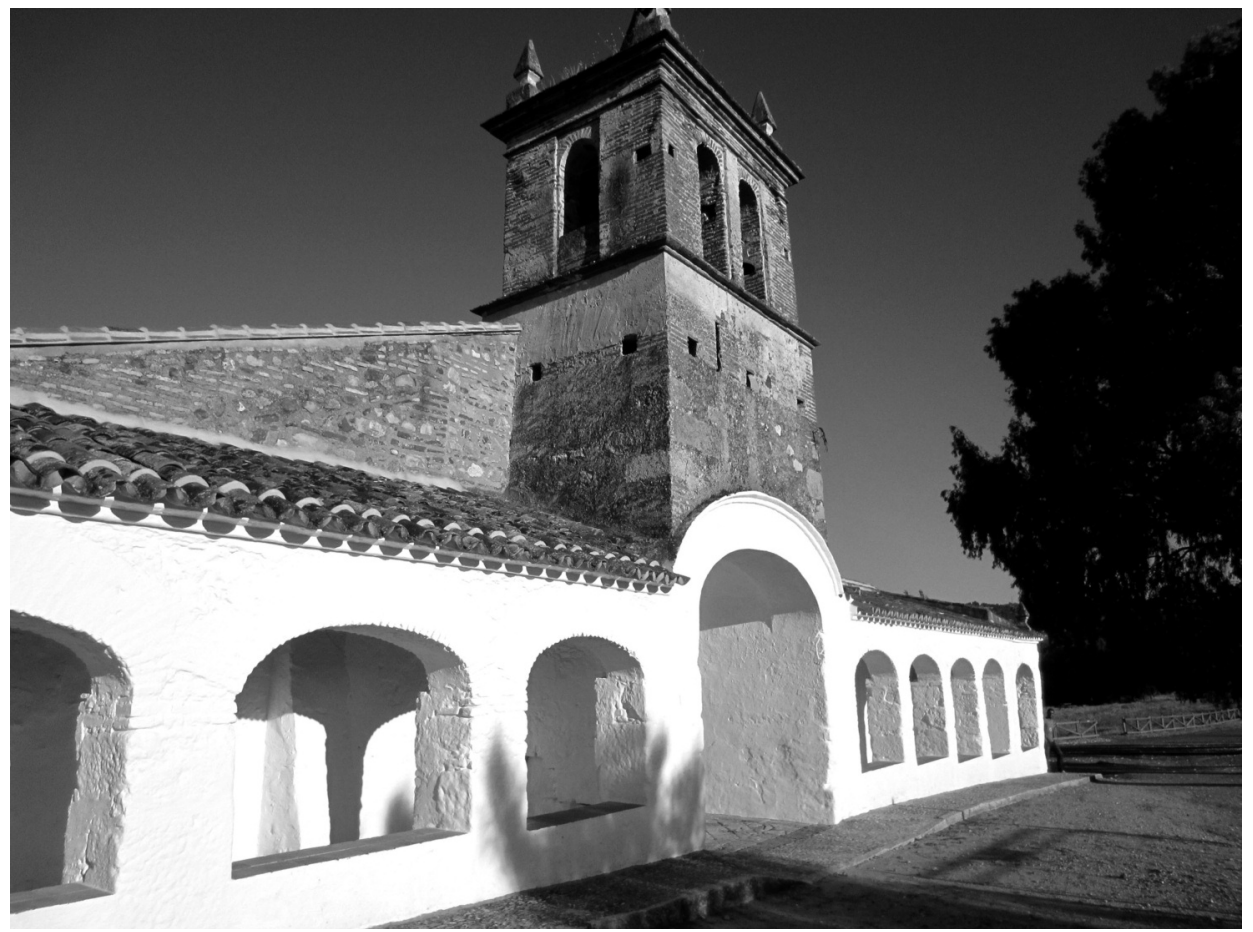

Fuente: Fernández Salinas, V. (Foto realizada en junio de 2014).

d) Mezquitas, en Almonaster la Real, construida sobre los restos de una antigua basílica visigoda (s. VI). Posee un valor excepcional por ser la única mezquita andalusí inserta en el medio rural y porque constituye un hito destacado (véase la figura 5) desde el que se obtienen imponentes vistas de las sierras centrales.

e) Bosques de castaño de las umbrías de las sierras centrales (Castaño del Robledo). Fueron introducidos en los siglos XV y XVI en áreas de antiguos robledales y con sus troncos fantasmagóricos (debido al sistema de podas) singularizan y connotan ciertos parajes; tanto es así que la hoja de castaño es el emblema del Parque Natural. 
FIGURA 5

MEZQUITA DE ALMONASTER LA REAL

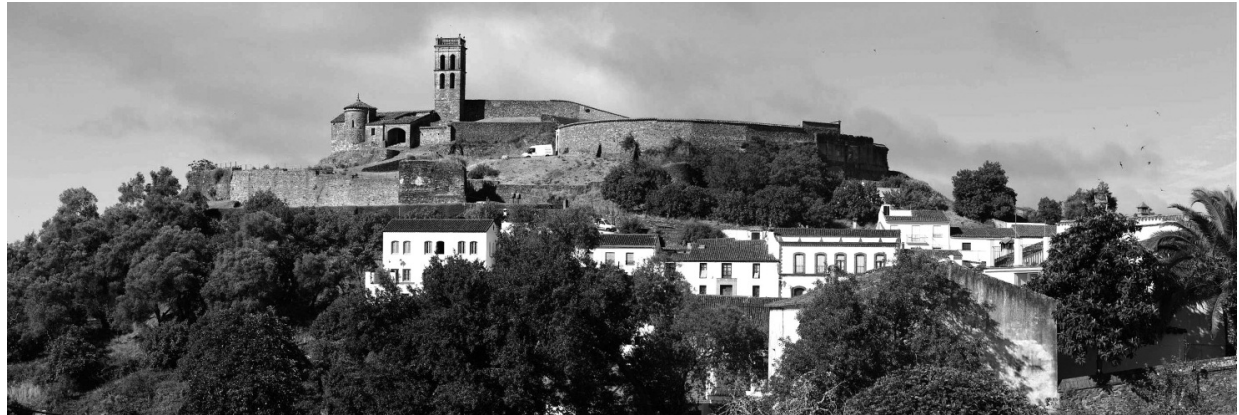

Fuente: Fernández Salinas, V. (Foto realizada en junio de 2014).

f) Dehesas, también con dos concreciones: 1) Llanos de la Belleza (Aroche, véase la figura 6), que, como ya se ha dicho, alberga en su interior la ciudad romana de Turobriga, la ermita de San Mamés y numerosos yaci-

\section{FIGURA 6}

VISTAS DE LOS LLANOS DE LA BELLEZA DESDE AROCHE

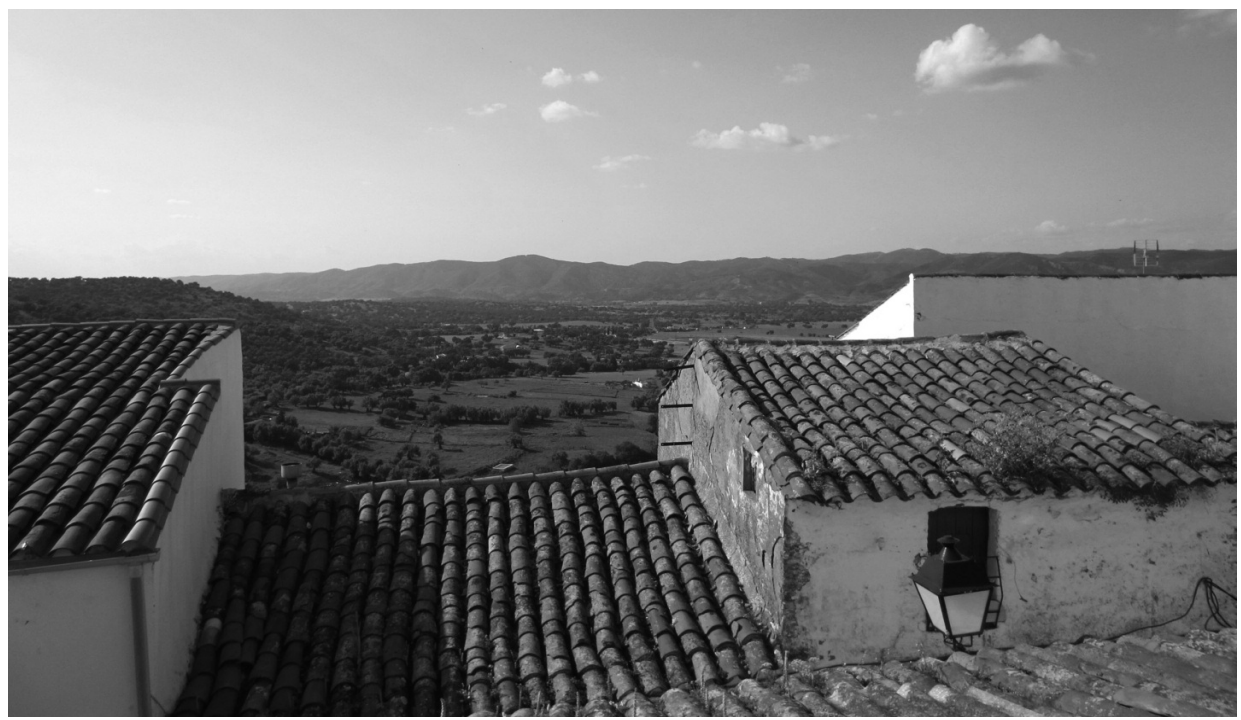

Fuente: Fernández Salinas, V. (Foto realizada en marzo de 2015).

Estudios Geográficos, Vol. LXXVII, 281, pp. 647-670, julio-diciembre 2016 ISSN: 0014-1496, eISSN: 1988-8546, doi: 10.3989/estgeogr.201622 
mientos neolíticos y calcolíticos; y 2) Alcornocales de Cala, que es un espectacular paisaje de alcornoques centenarios de los alrededores de esa localidad, reconocidos como Paisaje Agrario Singular por los Planes Especiales de Protección del Medio Físico (mediados de la década de los ochenta del siglo pasado) y donde se sitúa La Encina de San Francisco recientemente declarada Monumento Natural.

g) Artesanías del cerdo ibérico, también con dos ubicaciones: El Repilado y Jabugo en las sierras centrales y el núcleo urbano de Cumbres Mayores en las penillanuras del Noroeste. El ideario colectivo local percibe estas artesanías desvinculas del paisaje de la dehesa; de ahí la reciente propuesta de inscripción del jamón de Jabugo como Patrimonio Inmaterial de la Humanidad de Unesco, presentada por el Ayuntamiento de Jabugo para un ámbito donde se concentran las instalaciones industriales pero con una escasa significación paisajística de la dehesa. En nuestra opinión ambos vectores patrimoniales (dehesa y artesanías del cerdo ibérico) no deberían disociarse.

h) La cultura del agua, también concentrada en dos ámbitos: 1) CañaveralHinojales- Arroyomolinos de León, en las sierras calizas del Nordeste, con referentes muy destacados como el aljibe comunal Fuente-Redonda-La Laguna (Cañaveral de León, declarado BIC en la categoría de Lugar de Interés Etnográfico) y los molinos hidráulicos de Arroyomolinos de León; y 2) Sierras centrales, con numerosos referentes patrimoniales vinculados a la cultura del agua: ruedos de microparcelas irrigadas cercadas por muros de piedra (huertas de Galaroza), elementos lineales de una gran impronta visual (acequias o «lievas» y muros de piedra), elementos urbanos (Fuente de los Doce Caños de Galaroza y lavaderos de Linares de la Sierra, Higuera de la Sierra y Aracena) y elementos puntuales dispersos por el medio rural (molinos hidráulicos). 
DISTRIBUCIÓN TERRITORIAL DE LOS VECTORES PATRIMONIALES DE LOS PAISAJES SERRANOS ONUBENSES

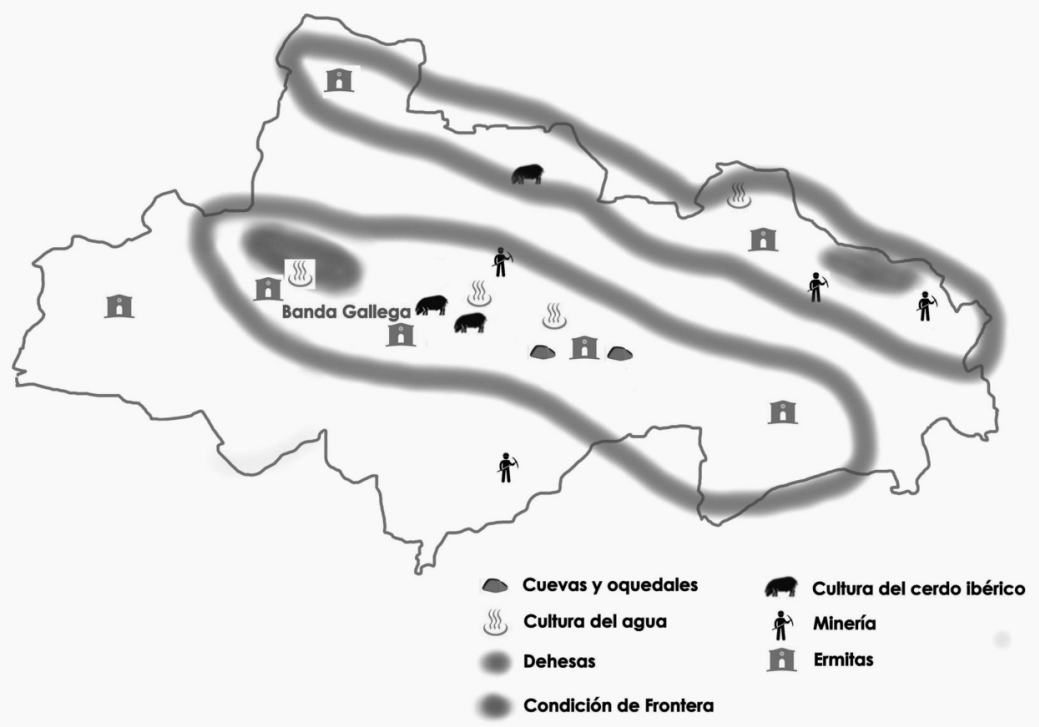

Fuente: elaboración propia a partir de la tabla 2.

La mayor parte de los vectores patrimoniales identificados están presentes en las sierras centrales, que se erigen en razón de ello en un área de elevada densidad patrimonial (véase la figura 7). Como ámbito de densidad patrimonial de tipo medio cabe destacar los Llanos de la Belleza donde, como se ha visto, se produce una confluencia de diversos vectores patrimoniales (paisajes de dehesa, ermita de San Mamés y ciudad romana de Turóbriga) y Cala (con una importantes presencia de antiguas minas romanas dispersas entre dehesas de quejigos, encinas y alcornoques). Otros ámbitos se caracterizan por su especialización patrimonial: son los casos del eje Cañaveral, Hinojales, Arroyomolinos de León (caracterizado por su patrimonio hidráulico) y de Cumbres Mayores (con una especialización patrimonial en las artesanías del cerdo ibérico). Los castillos de la Banda Gallega presentan una mayor ubicuidad y conforman una doble línea que hilvana buena parte de las poblaciones y vectores patrimoniales de esta sierra. 


\subsection{Procesos y actores de la patrimonialización}

La Sierra de Huelva ha sido objeto de intensas y multifacéticas filiaciones patrimoniales. En una fecha tan temprana como 1895 se operan las declaraciones del Castillo de Cumbres Mayores y de la Torre de las Harinas de Zufre. Se abre con ello una primera etapa de reconocimiento institucional, previa a 1985, de carácter principalmente monumental y urbano, marcada por el Decreto de 22 de abril de 1949 -que protege de forma genérica todos los castillos españoles- y por la incoación, en los primeros años de la década de los ochenta del siglo pasado de 13 Conjuntos Históricos $\mathrm{BIC}^{7}$, un número excepcionalmente elevado habida cuenta de la ubicación mayoritaria de los Conjuntos Históricos andaluces en grandes ciudades y su escasez en el medio rural. En la actualidad el número de BIC de esta sierra supera el medio centenar: a los Conjuntos Históricos hay que sumar más de una veintena de monumentos (entre castillos, iglesias y conventos), diversas Zonas Arqueológicas y un Lugar de Interés Etnográfico (el sistema hidráulico de Cañaveral de León ya comentado). El número de bienes inscritos en el Catálogo General de Patrimonio Histórico Andaluz asciende a 35 e integra un número considerable de cerros; algunas cuevas, fuentes, ermitas y plazas de toros; y diversas actividades de interés etnológico.

En 1985 se inicia una segunda etapa de patrimonialización institucional (1985-2000), que puede considerarse como una «fase de consolidación» coincidente con un traspaso de competencias desde el Estado central a la Junta de Andalucía. Su principal referente normativo es la disposición de la Ley 2/1989, de Inventario de Espacios Naturales de Andalucía a cuyo amparo se declara ese mismo año el Parque Natural Sierra de Aracena y Picos de Aroche (186.795 ha) y el Paraje Natural Sierra Pelada y Rivera del Aserrador (12.226 ha). La disposición en 1991 de la primera Ley de Patrimonio Histórico Andaluz perfila las políticas en materia de cultura. El resultado de todo ello es una notable expansión superficial de los territorios.

El año 2000 inaugura una última fase, que cabe calificar de «retoque patrimonial», apoyada en las declaraciones del Paraje Natural Peñas de Aroche (725 ha), el Paisaje Protegido Corredor Verde del Guadiamar (2.706 ha) y el Conjunto Histórico de Linares de la Sierra. En 2003 los espacios naturales se

7 Si bien buena parte de los Conjuntos Históricos serranos han sido declarados después de 1985, se ha utilizado la fecha de incoación del expediente, en lugar de la declaración, por cuanto la incoación implica el reconocimiento institucional mediante un régimen especial (y provisional, hasta que se produce la declaración) de protección. 
integran en la Red Natura, a la que también se incorporan la Rivera del Chanza (69,84 ha) y Mina Carpio (11,21 ha). Un año antes se había declarado la Reserva de la Biosfera Dehesas de Sierra Morena en el marco del Programa $\mathrm{MaB}$ de Unesco, que integra, además del Parque Natural Sierra de Aracena y Picos de Aroche, el de la Sierra Norte de Sevilla y el de la Sierra de Hornachuelos en Córdoba.

FIGURA 8

PROCESOS DE PATRIMONIALIZACIÓN INSTITUCIONAL EN LA SIERRA DE HUELVA

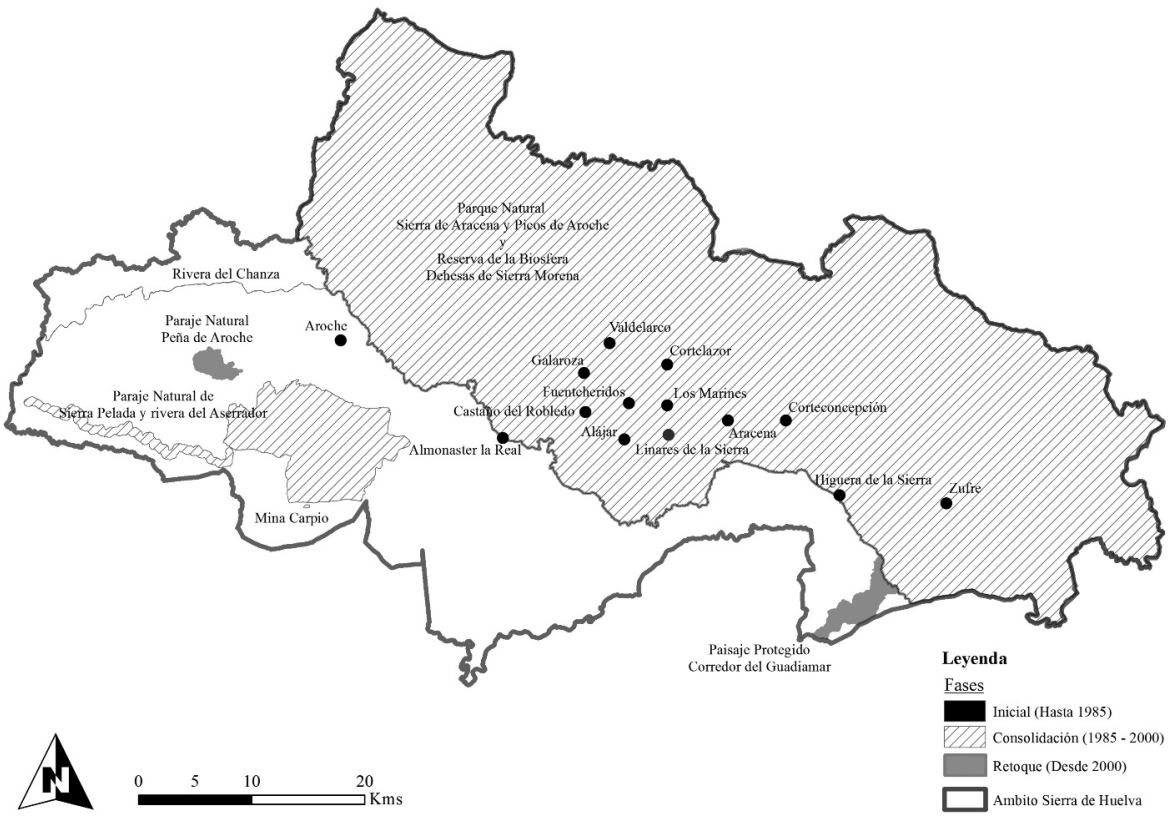

Fuente: Registros de Bienes de Interés Cultural y Espacios Naturales Protegidos. Elaboración propia.

Los procesos de patrimonialización «de abajo arriba» o inducidos por la sociedad civil también tienen un papel destacado en la Sierra de Huelva. Uno de sus principales exponentes son las jornadas anuales de patrimonio que se vienen celebrando casi ininterrumpidamente desde 1985: un total de 31 jornadas entre aquella fecha y 2016, repartidas entre 25 de municipios. Algunas poblaciones han acogido este evento en más de una ocasión, lo que cabe interpretarse como una elevada intensidad en lo que al proceso de patrimonia- 
lización «de abajo arriba» se refiere. Ello se completa con el reconocimiento en 2006 de la Denominación de Origen Protegida Jamón de la Sierra de Huelva, que responde a un proceso de patrimonialización de carácter socioeconómico, y que amplía la distinción tradicional de la calidad del jamón de Jabugo a toda la comarca, lo que no ha estado exento de disputas y tensiones internas.

La plasmación territorial de todos esos procesos patrimonializadores, en su diversas modalidades y etapas, refleja la existencia de una zona de intensa valoración patrimonial en las sierras centrales, donde confluyen los reconocimientos patrimoniales de carácter institucional (en su doble y artificial diferenciación entre patrimonio natural y cultural) y los inducidos por la sociedad civil. Esta zona coincide a grandes rasgos con el área de elevada densidad patrimonial señalada a propósito del análisis de los vectores patrimoniales. Desde ese núcleo los procesos patrimonializadores irradian en varias direcciones: hacia el Oeste (Llanos de la Belleza y Raya de Portugal), hacia el Norte (Cumbres Mayores y zona de Hinojales-Cañaveral de León), hacia el Noreste (Ruta de la Plata) y hacia el Sur (Andévalo minero).

Los actores sociales e institucionales implicados en esos procesos de patrimonialización son múltiples y variados: la Federación de Asociaciones de la Sierra de Huelva que aglutina a una veintena de asociaciones culturales de toda la comarca; el Centro de Investigación de Estudio Serranos CIES constituido en 1994 para promover el estudio y la difusión del patrimonio natural y cultural; el Grupo de Desarrollo Rural Sierra de Aracena y Picos de Aroche encargado de la gestión de los planes de desarrollo (iniciativas Leader y Proder); el Consejo Regulador de la Denominación de Origen Jamón de Huelva; la Junta Rectora del Parque Natural Sierra de Aracena y Picos de Aroche; y un largo etcétera. Tales agentes y sus propuestas, algunas reforzadas como normativa (Plan de Ordenación de los Recursos Naturales, Plan de Ordenación del Territorio de Ámbito Subregional, Planes Generales de Ordenación Urbana, Planes de Desarrollo Sostenible) conforman un capital socio-institucional indispensable para la gestión integral de los paisajes serranos onubenses y para la preservación de sus valores y vectores patrimoniales.

\section{Algunas CONCLUSiONES}

Este artículo plantea un procedimiento metodológico para el análisis de los paisajes patrimoniales. Partiendo del análisis «carácter» se centra en la identi- 
ficación y localización los argumentos patrimoniales de los paisajes y en los procesos de su empoderamiento social e institucional, en virtud de lo cual los argumentos patrimoniales se convierten en vectores de patrimonialización y los paisajes en paisajes patrimoniales. Su aplicación a la Sierra de Huelva ha permitido abundar en los principales rasgos de su «carácter» paisajístico, que en si mismos son un valor patrimonial; a saber: la diversidad físico-natural y humana, la condición histórica de frontera y la pluralidad de sus escenarios y parajes.

En lo que a la patrimonialización se refiere, se ha planteado un método para identificar y sistematizar los argumentos y vectores patrimoniales de estos paisajes, según se trate de componentes materiales o inmateriales (o etnográficos); y también se han identificado a los agentes implicados en la patrimonialización y los procesos a través de los que esta se opera. Todo ello ha permitido constatar que los argumentos, los vectores y los empoderamientos patrimoniales son territorialmente selectivos; dicho de otra forma, existen determinados atributos territoriales particularmente favorables al empoderamiento patrimonial de los paisajes, entre los que se encuentran: 1) los componentes con especiales atribuciones identitarias (ermitas) y con fuertes connotaciones históricas y simbólicas (castillos e iglesias); 2) los parajes singulares, excepcionales o diferentes, como los castañares o el hábitat disperso; 3) la belleza de los vectores patrimoniales y la armonía compositiva de sus integraciones paisajísticas; y 4) los espacios mejor comunicados y más accesibles y visibles.

Todos esos atributos confluyen en las sierras centrales del eje Aracena-Cortegana. La concentración en ellas de buena parte de los vectores patrimoniales y su empoderamiento patrimonial generalizado (ya sea por parte de las administraciones ambiental y cultural, ya sea por la sociedad civil), convierten a estas sierras centrales en el principal área patrimonial (en lo que a densidad de vectores e intensidad de reconocimientos se refiere) y permite constatar la virtualidad de la propuesta.

\section{AgradeCimientos}

Este artículo se inserta en un programa de investigación sobre paisajes patrimoniales desarrollado a través de los siguientes proyectos de I+D+i: "Paisajes patrimoniales de la España Meridional Andaluza" (Ministerio de Economía y Competitividad, 2013-2015; referencia: CSO2012-39564-C0707); "Métodos e instrumentos para el reconocimiento de los paisajes patrimo- 
niales en Andalucía" (Proyecto de Excelencia Junta de Andalucía, 2013-2017; código: P12-SEJ-2024); y "Paisajes Culturales de la Lista de Patrimonio Mundial. Claves para la identificación y criterios para la gestión de dehesas y montados ibéricos y Olivares Mediterráneos" (Ministerio de Economía y Competitividad, 2015-2017), CSO2015-65787-C6-6-P.

\section{BiBLIOGRAFÍA}

Berque, A. (2009): El pensamiento paisajero, Madrid, Biblioteca Nueva, 144 pp.

Besse, J. M. (2009): Le goût du monde: exercices de paysage, Arles, Actes du Sud ENSP/Centre du Paysage, 229 pp.

Carmona Ruíz, Ma A. (1998): "La Explotación Ganadera de la Frontera Luso-Española: la "Contienda" de Moura, Nódar, Aroche y Encinasola", Revista da Faculdade de Letras, Serie Historia, Universidade do Porto, serie II, 15, pp. 241-251.

Clark, K. y Drury, P. (2002): "Du monument au citoyen: les fonctions du patrimoine culturel dans une Europe en évolution", en Conséil De l'Europe, Fuctions du patrimoine culturel dans une Europe en changement, Strasbourg, pp. 119-124.

Consejo de Europa (2000): Convenio Europeo del Paisaje, Florencia, Consejo de Europa.

Fernández Salinas, V. y Silva Pérez, R. (2015): "Paisajes españoles susceptibles de ser incluidos en la Lista de Patrimonio Mundial de Unesco. Criterios para su identificación y selección", Boletín de la Asociación de Geógrafos Españoles, 68, pp. 253-278.

Gómez Mendoza, J. (2013): "Del patrimonio paisaje a los paisajes patrimonio", Documents d'Anàlisi Geogràfica, 59/1, pp. 5-20.

Gómez Zotano, J. y Riesco Chueca, P. (2010): Marco conceptual y metodológico para los paisajes españoles. Aplicación a tres escalas espaciales, Sevilla, Centro de Estudios Paisaje y Territorio, Junta de Andalucía, 469 pp.

IAPH, Instituto Andaluz de Patrimonio Histórico (2010): "Sierra Morena de Huelva y Rivera de Huelva y Cala", en Instituto Andaluz de Patrimonio Histórico, Guía Digital del Patrimonio Cultural, Sevilla, Instituto Andaluz de Patrimonio Histórico, URL: http://www.iaph.es/web/canales/conoce-el-patrimonio/guia-digital/textos-e/Dermacacion_Sierra_Morena_de_Huelva/paisaje/index.html (consultado: 26/01/2015).

Junta de Andalucía (2005): "Mapa de los paisajes de Andalucía”, en Atlas de Andalucía. Tomo II, Sevilla, Consejería de Obras Públicas y Transporte y Consejería de Medio Ambiente, URL: www.paisajeyterritorio.es (consultado: 26/01/2015).

Martín Delgado, F. (1999): Poemas sueltos, Jabugo, Empresa Gráfica Rodríguez Domínguez, $40 \mathrm{pp}$.

Mata, R. (2010): "La dimensión patrimonial del paisaje: una mirada desde los espacios rurales", en J. Maderuelo (dir), Paisaje y patrimonio, Madrid, Ádaba, pp. 31-74.

Mata, R., De Meer, A. y De la Puente, L. (2012): "Sustainable development and making of territory and everyday landscapes as heritage - an experience in the 
Cantabrian mountains", en J. M. Feria (ed.), Territorial Heritage and Development, Londres, Taylor and Francis Group, pp. 141-158.

Mata, R. y Sanz Herráiz, C. (dirs.) (2004): Atlas de los paisajes de España, Madrid, Ministerio de Medio Ambiente, 683 pp.

Moreno Jurado, J. A. (1995): Canciones o paisaje, Huelva, Diputación Provincial de Huelva, $60 \mathrm{pp}$.

Moya, M. (1996): Íntimo. Sierra de Aracena y Picos de Aroche, Huelva, Iniciativas LEADER Sierra de Aracena y Picos de Aroche, 54 pp.

Ojeda, J. F. (2013): "Lectura transdisciplinar de paisajes cotidianos, hacia una valoración patrimonial. Método de aproximación”, Revista INVI, 28/78, pp. 27-75.

Ojeda, J. F. y Silva, R. (2002): "Efectos de la aplicación de modelos agroambientales y postproductivistas en la Sierra Morena onubense", Estudios Geográficos, 63/246, pp. 69-100.

Prats, L. (1997): Antropología y patrimonio, Barcelona, Ariel, 171 pp.

Recio Moya, R. (1995): Antropología de la Sierra de Huelva, Huelva, Diputación Provincial de Huelva, 400 pp.

Sánchez, C. y Castillo, R. (1999): El humanista Arias Montano, Huelva, Universidad de Huelva, $33 \mathrm{pp}$.

Scazzosi, L. (2004): "Reading and assessing the landscape as cultural and historical heritage", Landscape Research, 29/4, pp. 335-355.

Silva Pérez, R. y Fernández Salinas, V. (2015): “Aproximación de los paisajes patrimoniales a través de la Sierra de Huelva”, Ponencia impartida en las XXX Jornadas del Patrimonio de la Comarca de la Sierra, Zufre, 26-29 de marzo de 2015.

Villa, A. (2011): "La Raya Seca con Portugal como ejemplo de paisaje de las traseras y el abandono", en F. Molinero et. al. (coords.), Los paisajes agrarios de España. Caracterización, evolución y tipificación, Madrid, Ministerio de Medio Ambiente y Medio Rural y Marino, pp. 520-533.

Zoido, F. (dir.) (2012): "Macizo de Aracena y Corredor de la Plata", en Inventario de Paisajes de Andalucía, Sevilla, Centro de Estudios Paisaje y Territorio, Junta de Andalucía. URL: http://www.juntadeandalucia.es/medioambiente/portal_web/web/ temas_ambientales/paisaje/sistema_informacion_paisaje/a2_aracena_plata.pdf (consultado: 26/01/2015).

Fecha de recepción: 9 de febrero de 2015.

Fecha de aceptación: 22 de octubre de 2015. 